\title{
'So let's talk. Let's chat. Let's start a dialog': An analysis of the conversation metaphor employed in Clinton's and Obama's YouTube campaign clips ${ }^{1}$
}

\author{
STEVE DUMAN and MIRIAM A. LOCHER
}

\begin{abstract}
This paper examines how two American presidential candidates, Barack Obama and Hillary Clinton, make use of a VIDEO EXCHANGE IS CONVERSATION metaphor on YouTube, a channel of communication that allows the exchange of video clips on the Internet. It is argued that the politicians exploit the metaphor for its connotations of creating involvement and closeness and its potential as a persuasive strategy. They are, however, also restricted by the VIDEO EXCHANGE IS CONVERSATION METAPHOR: since the metaphor entails alternating speaker roles, the willingness of the addressee to engage in the exchange and to personally bond, the candidates have to construct a viewer identity and a candidate identity that matches the framework of the metaphor. In addition, the influence of the medium YouTube on the linguistic presentation is discussed in a close reading of the video clips, its main restrictions being currency (topicality and coherence), as well as asynchronicity, which results in a pseudo-dialogic character of the exchange.
\end{abstract}

\section{Introduction}

Video exchange, made possible by the Internet and by increasing computing power and storage capacity, represents a new and dynamic opportunity for human communication. This paper examines the campaign beginnings of two prominent U.S. American politicians who, for the first time in the history of U.S. elections, make use of this medium by presenting themselves in video clips to the Internet community. The focus of this paper is on the metaphor with which both politicians choose to present themselves and their campaigns and on how they are constrained by and exploit the restrictions imposed by the medium.

YouTube.com, the most prominent of video exchange websites to date, has rapidly proved successful since its initial development in February 
of 2005 (Associated Press 2006). YouTube users are able to view and share video clips from around the world in an asynchronic fashion, presenting themselves from anywhere they choose. Though video exchanging shares attributes of related media such as film and television, its distinct differences and uses are evident in its title, YouTube: the emphasis is on the active agent You, the expression Tube is a colloquial reference to television, and in addition YouTube's slogan is Broadcast yourself. It is a medium usable by anyone with a computer with Internet access and a video camera.

In January of 2007, with the 2008 U.S. presidential elections nearly two years away, high-ranking politicians turned to YouTube as a way to connect with the American public and potentially gather new votes. The first presidential candidates to engage in the medium were Senators Barack Obama and Hillary Clinton. Both candidates posted video clips on YouTube featuring themselves speaking to the viewer about their intentions to begin presidential exploratory committees, the first step in starting campaigns (Clinton 2007a; Obama 2007a). The 2008 election will be the first presidential election in which video exchange technology is at the candidates' disposal. Congruently, any use of YouTube by the candidates may be interpreted as a rhetorical technique, one specifically aimed at persuading the public and winning votes.

This use is contrary to what YouTube users predominantly post, namely video clips for informative or entertainment purposes. ${ }^{2}$ The use of such a forum for political, rhetorical intentions, combined with the very new and flexible technology of video exchange, offers us a unique opportunity to examine the birth and development of a new type of interaction. In providing a persuasive facet to the medium the candidates are forging new ground and testing its abilities and potentials. ${ }^{3}$ Simultaneously, they are shaping the way future users will engage in it. They are, in essence, experimenting with an entirely new way of connecting with the public by means of visual technology and allowing new methods of audience engagement. Users may, for example, post text responses as well as video responses to existing clips, as well as list links to their favorite clips on their individualized YouTube sites.

In each of the analyzed video clips, the candidates look into the camera, address the viewer directly with the second person you, and even claim that their clips are the first part of a conversation. While the Oxford English Dictionary defines conversation as an '[i]nterchange of thoughts and words; familiar discourse or talk' (1989, online), we argue that the candidates construct their contributions not just as opportunities for the exchange of ideas, but they also wish to create an illusion of a face-toface and personal conversation. Since the candidates explicitly evoke the concept of conversation, which entails input of different parties, they 
implicitly invite reactions to their contributions. In a face-to-face conversation, such reactions can be immediate, while the technological restrictions of YouTube allow only for asynchronous turns. We maintain that immediacy is a crucial feature of conversation, which is lacking in asynchronous communication: ${ }^{4}$ to treat asynchronous video exchange as a synchronous conversation is thus a metaphor for the actual communicative event, which we will refer to as a VIDEO EXCHANGE IS CONVERSATION metaphor. The video aspect is self-evident, as it is the name of the finished visual product when one uses a video camera to record something. ${ }^{5}$ The term exchange is important because it highlights the ability - not the obligation - of users to post a video or text message in response. The video exchange aspect of YouTube makes it interactional and imitates face-to-face conversational interaction.

The intention of this paper is to explore the medium YouTube and the VIDEO EXCHANGE IS CONVERSATION metaphor and their implications for the linguistic strategies and choices of both addresser and addressee. These strategies include but are not limited to face-threatening, facesaving and face-enhancing, as well as identity construction of both the addresser and the addressee (both of whom influence the interaction). These terms need some explanation since they form the theoretical background of this paper. They are an essential part of the concept of relational work, which is defined as

the 'work' individuals invest in negotiating relationships with others. Human beings rely crucially on others to be able to realize their life goals and aspirations, and as social beings they will naturally orient themselves towards others in pursuing these goals.

(Locher and Watts 2005: 10)

Locher and Watts (2005: 10-11) suggest relational work as an alternative term to facework, employed in politeness research, which they feel has been used too often in literature by scholars such as Brown and Levinson ([1978] 1987) to describe mitigation strategies for face-threatening acts only. However, instead of focusing specifically on politeness, relational work refers to the entire spectrum of the interpersonal aspect of interaction (cf., e.g., Watts 1992, 2003, 2005; Locher 2004, 2006a; Locher and Watts 2008).

Clearly, face constitutes an important aspect of relational work. Face is a concept prominently used by Goffman (1967: 5) and is defined as 'the positive social value a person effectively claims for himself by the line others assume he has taken during a particular contact'. ${ }^{6}$ Face, therefore, is neither static nor exclusive to the person engaging in the interaction. As Locher and Watts (2005: 12) explain, '... [f]ace does not 
reside inherently in an individual ... but is rather constructed discursively with other members of the group in accordance with the line that each individual has chosen.' In other words, face is a metaphor for the different ways an individual opens him/herself to interpretation and in turn is evaluated by the audience in a given social interaction. Both relational work and face highlight the importance of speaker and hearer in a given speech event. In addition, the notion of face is intricately linked to considerations of identity construction, a line of thought that we will pursue in this paper. Though this study does not discuss politeness issues per se, it uses relational work as a model for categorizing and explaining the linguistic choices adopted, encouraged and/or necessitated by the video exchange medium and the VIDEO EXCHANGE IS CONVERSATION metaphor.

This paper is organized as follows: in Section 2, we will introduce the data we intend to study: Obama's (2007a) My Plans for 2008 and Clinton's (2007a) I'm In. In Section 3 we will first discuss aspects of Lakoff and Johnson's (2003 [1980]) conceptual metaphor theory and argue for the multimodal aspect of the VIDEO EXCHANGE IS CONVERSATION metaphor. The facets introduced in this section provide the foundation for the discussion that follows. We will present the restrictions imposed by the medium, which directly affect linguistic choices, from currency (topicality and coherence) in Section 4 to asynchronicity in Section 5, both of which have an impact on the linguistic construction of the candidate's identity as well as the construction of the viewer's identity. In Section 6, we will briefly present an overview of how the candidates continued their campaigns before concluding in Section 7.

\section{Data: The artifacts}

Politics and visual media are no strangers. From the oft-cited Kennedy/ Nixon televised debate (Tracey 1995: 123) to modern scandals, political figures have learned that there is no escape from the public eye. In 1952, television played its first major role in a presidential election, helping Dwight Eisenhower appeal to the public and acquire office (Smith 1988: 398). The switch to television as a major source of political persuasion brought with it a new type of politics. As Hedrick Smith (1988) explains:

TV gives viewers a direct experience of political leaders and gives politicians direct access to the living rooms of the electorate. This immediacy fuels the politics of emotions, gut reactions, and impressions rather than the politics of logic, facts, and reason; it emphasizes personality rather than issues.

(Smith 1988: 399) 


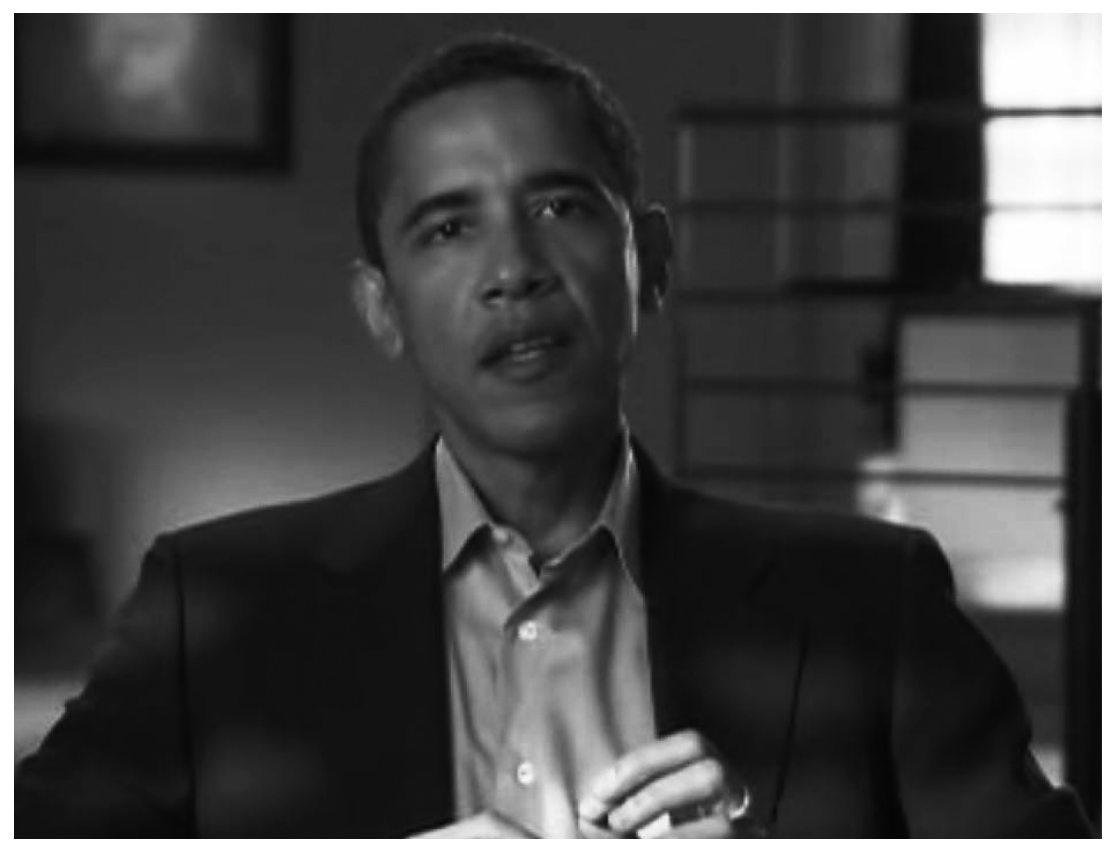

Screenshot 1. Barack Obama in My Plans for 2008 (courtesy of barackobamadotcom).

The emphasis on the personality and physical appearance of candidates remains an important element of a campaign. In fact, the technology of video exchange websites such as YouTube offers a new perspective to this claim. No longer are the candidates presented by just television or print media. Instead, they may now present themselves directly to the audience, portraying themselves to the public specifically as they wish to be portrayed.

The first politician to enter this arena was the Democratic Senator from Illinois Barack Obama. Obama's (2007a) video entitled My Plans for 2008 (559 words) was posted on January 16, 2007 and lasts 3 minutes and 7 seconds. The video features the young Senator looking into the camera. He sits in a relaxed position in a non-descript room that could either be a living room area or an office that features no personal effects (see Screenshot 1). He is well dressed but rather informal, sporting a suit jacket but no tie - in fact, his top shirt button is unbuttoned (see Appendix for the transcription conventions and the full text).

Six days later, on January 22, 2007, the Democratic Senator from New York Hillary Clinton (2007a), former First Lady of the United States, 


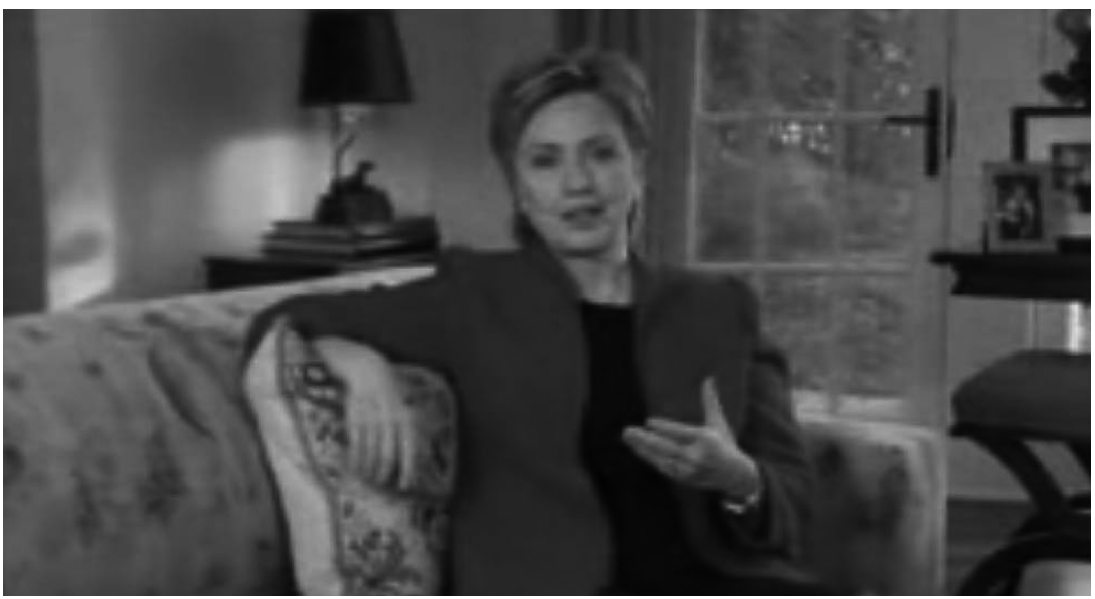

Screenshot 2. Hillary Clinton in I'm In (courtesy of hillaryclintondotcom).

posted her video entitled I' $m$ In. With only one minute and 53 seconds (317 words) it is considerably shorter than Obama's. In contrast to Obama, Clinton clearly sits in a living room that even displays family pictures. She is professionally dressed and sits on a couch, occasionally leaning onto a pillow at her side (see screenshot 2). Unlike Obama's video, where the camera remains static, Clinton's video displays a moving perspective: the camera pans slowly back and forth and she is featured from medium shot to close-up perspectives through various edit cuts (Prince [2007]; see Appendix for the full transcription).

Both videos serve as announcements that the Senators will form presidential exploratory committees, the first step in beginning campaigns to run for president of the United States in the upcoming 2008 election. In our analysis we will mainly focus on these two clips that mark the beginnings of the YouTube campaigns of the two Senators. In Section 6, however, we will briefly touch on further clips that were posted later. By posting videos on YouTube, the candidates have already demonstrated innovativeness regarding their campaigns. Not coincidentally, presidential hopefuls Obama and Clinton occupy non-traditional social positions in the race. Obama could potentially be the first African American man to take office, while Clinton could be the first woman to become president. In a long line of Caucasian, male presidents, this makes their campaigns particularly noteworthy. It is also remarkable that, at least within the first month of the candidates posting their videos, no other potential candidates followed in their footsteps. 


\section{The video exchange is conversation metaphor}

\subsection{Theoretical background: Conceptual and multimodal metaphors}

The seminal work by Lakoff and Johnson (2003 [1980], 1999) and Lakoff (1987) provide a structural framework for this paper. Underlying Lakoff and Johnson's Conceptual Metaphor Theory is the notion of concepts. As Cruse (2004: 125) explains, '[c]oncepts are vital to the efficient functioning of human cognition. They are organized bundles of stored knowledge which represent an articulation of events, entities, situations, and so on in our experience.' Concepts, therefore, are highly complex 'bundles of knowledge' acquired by individuals through the experience of interacting with other members of a community. They represent the building blocks of semantics, or how humans express and perceive meaning through language. Conceptual Metaphor Theory therefore differs from conventional views of metaphor because, as Knowles and Moon (2006: 32) elaborate, it describes 'conceptual metaphors, and they relate to concepts, not to individual lexical items' (emphasis in original). Lakoff and Johnson (2003) develop Conceptual Metaphor Theory through their thesis that human thought is largely metaphorical in nature and that this is expressed through language. Lakoff and Johnson (2003: 5) thereby understand the notion of metaphor as follows: 'The essence of metaphor is understanding and experiencing one kind of thing in terms of another' (italics removed). From this basic definition, they reveal how the use of a metaphor is not a novel, substitutive language technique, but rather a method of 'mapping' the meaning of a concrete, salient concept onto a more abstract, less tangible concept.

Metaphor, therefore, involves the mapping of concepts onto one another, creating an 'interaction', as philosopher Max Black (1962: 79) would call it, a creation of meaning for which there is no appropriate, literal equivalent. In Lakoff and Johnson's (2003) terms, elements of the source domain, the more concrete or common (often physiological), are projected upon the more abstract target domain. One of their primary examples, the ARGUMENT IS WAR (or STRUGGLE) ${ }^{7}$ metaphor, helps illustrate this point:

\section{ARGUMENT IS WAR}

Your claims are indefensible.

He attacked every weak point in my argument.

I demolished his argument.

I've never won an argument with him. (Lakoff and Johnson 2003: 4)

It is important to note that Lakoff and Johnson do not view the linguistic realizations of the ARGUMENT IS WAR metaphor as metaphors in and 
of themselves, but rather as evidence of the larger interaction of the source domain WAR being projected upon the target domain ARGUMENT. Such linguistic expressions are evidence of our dependence upon conceptual frameworks.

Limiting descriptions of conceptual metaphors to linguistic realizations, however, is problematic. As Forceville (2006: 2) argues, metaphors are 'expressed by language' but are not 'necessarily linguistic by nature' (italics removed). Though a linguistic expression such as ARGUMENT IS WAR provides a way of referencing the metaphor, it fails to take the complexities of both the metaphor and the involved concepts into account. Therefore, to consider metaphors in communicative forums, we must also consider the various modes through which conceptual metaphors might be realized. Though Forceville (2006: 3-4) admits the near impossibility of providing an exact definition of mode, he maintains that 'a mode is a sign system interpretable because of a specific perception process', which would therefore include '(1) pictorial signs; (2) written signs; (3) spoken signs; (4) gestures; (5) sounds; (6) music; (7) smells; (8) tastes; (9) touch'. Conceptual metaphors which involve more than one of these modes are known as multimodal metaphors. Because the videos in the analysis that follows include visual (or pictorial) signs and spoken signs, a multimodal approach will help explain how these modes interact to create the metaphor and affect the candidates' linguistic choices.

As mentioned above, we examine the VIDEO EXCHANGE Is CONVERSATION metaphor as a conceptual, multimodal metaphor. Therefore, we will elaborate on the metaphor, in particular the ways in which the different modes, especially the speech and visual modes, interact. This analysis will include a discussion of the source and target domains, the linguistic and visual exploitations of the metaphor, the necessary highlighting and hiding of such a metaphor, and the implications of using the metaphor as a tool for political persuasion.

\subsection{Source and target domains}

As previously mentioned, the video aspect of VIDEO EXCHANGE IS CONVERSATION relates to the fact that we are dealing with a visual medium of recorded speech messages. The term exchange highlights the possibility of users reacting to the clip by either posting a textual message in a comments field or by posting response videos which are directly linked to the original video. Therefore, though users may choose to only watch the initial videos, every registered user may provide a response video to a posted video which will be accessible to all other viewers and appear as a link directly beneath the original video. 
In the VIDEO EXCHANGE IS CONVERSATION metaphor, the concept CONVERSATION serves as the source domain. A conversation is a fundamental form of human interaction which is mapped upon the target domain, i.e., the exchange of videos by people using YouTube, which constitutes the more abstract interaction. The concept CONVERSATION is seen as two individuals in an '[i]nterchange of thoughts and words', thus taking turns in 'familiar discourse or talk' (Oxford English Dictionary). In face-toface or telephone interactions this turn-taking has a quality of immediacy since the interactants can react to each other's contributions without delay. We therefore propose that 'immediacy' is a crucial aspect of the concept of CONVERSATION. As argued at the beginning, to treat asynchronous video exchange as a conversation is thus a metaphor for the actual communicative event. ${ }^{8}$

In addition, we understand a two-party conversation as consisting of at least six primary dimensions, as outlined by Lakoff and Johnson (2003: 77-78): 'participants, parts, stages, linear sequence, causation, and purpose'. A conversation is a basic human experience because, as human beings, we encounter conversations consisting of these dimensions on a daily basis as an essential aspect of our survival. Of course, the concept CONVERSATION can itself be constructed by other concepts which are understood metaphorically (Lakoff and Johnson 2003: 97). To illustrate this, we can look at some of these metaphors by examining collocations, as reported in the Oxford Collocations Dictionary for Students of English (2002) and as evidenced in the British National Corpus (BNC):

A CONVERSATION IS A MOVING OBJECT ON A PATH

I tried to steer the conversation in the right direction.

I had trouble following the conversation.

The conversation started/continued/stopped.

There was a lull in the conversation.

The conversation was moving into dangerous territory.

It was tough to get the conversation back on track.

They kept the conversation going all night.

A CONVERSATION IS A PHYSICAL BOND

I was stuck in a conversation with him.

I couldn't get out of the conversation.

They were engaged in conversation.

He kept talking - I couldn't break away from him.

We were tied up in a conversation.

In addition, the three most frequent predefining adjectives that collocate with conversation in the $\mathrm{BNC}$ are private, deep and long, all of which 
imply intimacy or extended interaction between conversants. We argue that, when the candidates use the VIDEO EXCHANGE IS CONVERSATION metaphor, they exploit the above metaphors and collocations to strengthen the potency of the interaction. Clinton and Obama invite the viewer on a journey as 'passengers' on the path towards Election Day, during which they will bond with the candidate and engage in (simulated) personal face-to-face interaction, i.e., a pseudo-dialog.

Like other media, YouTube combines the visual and spoken modes, but, when the candidates explicitly evoke the concept of CONVERSATION, ${ }^{9}$ the interaction becomes grounded in expectations that we have with respect to face-to-face conversations. Both Hillary Clinton and Barack Obama explicitly use the term conversation in their contributions. The VIDEO EXCHANGE IS CONVERSATION metaphor is thus developed through the interaction of the spoken mode with the visual mode, that is the actual visual representation of the candidates in the imitation of face-toface interaction. Without these two modes, the metaphor would not work; the exchange would be composed of only written language. The visual and spoken modes allow for a simulation of a face-to-face conversation, and the candidates simultaneously support the interpretation of the exchange as a conversation within their pseudo-dialogs, i.e., by constructing their contributions as first turns in an implied sequence of exchanges.

With respect to the construction of a first turn in the 'conversation', it is vital to stress that asynchronicity and asymmetry go hand in hand. In the first turn the conversation is asymmetrical in favor of the candidates, as the viewer cannot immediately respond or interrupt. The candidates can produce carefully designed artifacts, in which they construct both their own and the addressee's identities in this first turn, which is a powerful move (see Section 5). However, in case a viewer decides to respond, the same power is available to him or her.

\subsection{Linguistic and visual exploitations of the metaphor}

The metaphor manifests itself in two primary ways: (1) on a linguistic level, where both candidates actually refer to the video and their upcoming campaigns as conversations, and (2) on a meta-level, which includes but is not limited to the interaction between the visual and spoken modes. First we turn to the different linguistic realizations of the VIDEO EXCHANGE IS CONVERSATION metaphor as evident in each video. Obama (2007a) concludes his video in extract (1) (for transcription conventions see the Appendix): 
(1) O: 71 and I look forward to continuing our 'conversation.

O: 72 in the 'weeks and 'months to come.

Obama's use of conversation as quoted here functions as a comment on the video, one which puts into words the multimodal metaphor which he employs. It is his first and only direct reference to the interaction as a conversation within the entire video.

Clinton (2007a), on the other hand, is much more direct about the metaphor from the very beginning as evidenced in (2):

(2) C: 1 I I announced today that I'm forming a 'presidential exploratory committee.

2 'I'm not just starting a campaign though I'm beginning a conversation.

3 with 'you.

4 with ^America.

5 because we ^all need to be part of the 'discussion if we're ^all going to be part of the 'solution.

6 and ^all of us ^have to be part of the solution.

Clinton very much embraces the idea of a conversation or discussion, as her campaign slogan even reads 'Let the Conversation Begin' (Clinton $2007 \mathrm{~b}, \mathrm{c}, \mathrm{d})$. On the surface level, this makes her not a politician first and foremost, but rather a concerned citizen who would simply like to talk over the issues.

When the visual and spoken modes are taken into account, the VIDEO EXCHANGE IS CONVERSATION metaphor defines the video exchange as a whole. The candidates are the speakers and the viewer, who may respond, is a participating conversant. In both videos, the candidates sit facing the camera, effectively simulating eye contact. Both candidates are speaking at the camera presumably to imply engagement with the viewer. In their work Reading Images, Kress and van Leeuwen (2006) explain that

[t]he system of perspective which realizes 'attitude' was developed in the Renaissance, a period in which individuality and subjectivity became important social values, and it developed precisely to allow images to become informed by subjective points of view.

(Kress and van Leeuwen 2006: 129)

In this way, the perspective or point of view provided by the form of mediation, in this case the camera, 'implies the possibility of expressing subjective attitudes towards represented participants, human or otherwise' (ibid.). The camera's perspective encourages the viewer to make a subjective interpretation. We argue that the camera angles in both Oba- 
ma's and Clinton's videos encourage an interpretation of the broadcast as a conversation. The candidates stare into the camera at an even angle: they are the primary visual subjects looking at an implied viewer. As such, the audience is encouraged to view the candidates as conversational partners. Directly complementing the visual element is the spoken mode, where the candidates (by looking at the viewer) are simultaneously talking to the viewer. This congruently manifests itself through the use of the second person you and the pronoun we, a subject discussed later.

The visual element in both videos creates a bond with the viewer. The candidates clearly want something from the viewer, hence they position themselves in the clip in such a way that the viewer's attention is directed at them. First, Obama's video features a fixed perspective; the camera remains motionless with a medium shot of the Illinois Senator (see Appendix). The distance suggests relative intimacy, as the viewer and he are close enough to converse and no one else is present. This suggests the frame of a private conversation. The static camera locks the viewer into position, effectively leaving nothing to focus on but Obama himself. While he moves his hand slightly throughout the clip, he is sparse with his pronounced hand motions, using them to emphasize only certain points. Indeed, Obama does not move his body at all throughout the interaction. He maintains his seated position and thus gives the viewer nothing to focus on beyond his eye contact and his words.

The camera in Clinton's video is far from static (see Appendix). It slowly pans from left to right and then back again throughout the duration of the video. In addition, the camera positioning changes between a medium shot, a close-up, and back to a medium shot. The medium shot allows more of the room to be visible than Obama's video. This gives the viewer more to look at, such as the family pictures or the yard outside. The moving camera thus creates a less locked position for the viewer. A possible interpretation of this is that the close-up imitates everyday space conventions, suggesting greater intimacy between Clinton and the viewer (Messaris 1994). The closer the viewer is to the subject, the more personal or 'intense' the interaction. Alternatively, one might argue that the camera movement de-emphasizes the metaphor's effect because it foregrounds filmic conventions.

During the close-up, Clinton stresses the important, divisive subjects around which she thinks the conversation should revolve (such as the troops in Iraq or health care). Unlike Obama, Clinton presents herself as more physically dynamic. On two occasions, she lightly leans against a pillow just behind her, creating the illusion of a relaxed exchange. In her concluding thoughts, she leans forward to emphasize: Let's talk. The 
camera focus on both candidates as main subjects at an even angle, combined with the subjects' continual eye contact, and direct speech, make the VIDEO EXCHANGE IS CONVERSATION possible.

\subsection{Highlighting and hiding}

A fundamental aspect of conceptual metaphors is their tendency to highlight certain aspects of the source domain while simultaneously hiding others. When discussing the ARGUMENT IS WAR metaphor, Lakoff and Johnson (2003: 10) explain highlighting and hiding by indicating that such a metaphor concentrates on (or highlights) the battle aspects of an argument but places little to no emphasis on (or hides) the equal if not more important aspect of cooperation. The VIDEO EXCHANGE IS CONVERSATION metaphor is no exception in its tendency to hide some and to highlight other aspects.

What is highlighted from the concept of CONVERSATION is the personal aspect. Given the fact that posting a video on YouTube is the Internet equivalent to broadcasting to a national or world-wide audience, this is of course an illusion. In addition, the exchange of points of view is evoked. In their first clips, the candidates provide two to three minutes of uninterrupted monolog that they frame as the beginning of a conversation. A viewer is thus implicitly invited to respond but is not obligated to do so. ${ }^{10}$ The only way for this to be interpreted as a conversation is to conceptualize each clip as a turn in a conversation.

However, what is hidden, or de-emphasized, are the aspects of immediacy/synchronicity. They are only implied by the metaphor. In other words, the metaphor hides the fact that technical limitations of YouTube do not permit the immediacy/synchronicity of conversation. There is no interaction within each individual clip.

\subsection{The metaphor as a persuasive strategy}

One essential aspect of the VIDEO EXCHANGE IS CONVERSATION metaphor in the context of these two videos is that both candidates have unambiguous intentions to persuade: both want to be the next president of the United States. Though candidates already make extensive use of rally speeches, brochures, commercials, phone calls, and the like to gather public support, YouTube provides a new forum for political persuasion. In its resemblance to conversation, it implies an immediacy and personal touch lacking in traditional methods. This is especially important for the viewer, who may now be represented by more than a concerned letter, i.e., by a visual representation of him/herself achieved by means of a video clip. We argue that this possibility, whether used or not, helps to 
construct the idea of an equal, symmetrical conversation. The viewer's ability to converse back with the candidate - through the very same video forum - empowers the viewer. In other words, video exchanging simulates political deliberation by creating the illusion of immediate exchange. Current research by Seong-Jae Min (2007) suggests that online deliberation might be nearly as effective in developing citizens' 'political participation' and thus 'political efficacy' as face-to-face deliberation. Min's research, however, is not based on video data and thus clearly lacks the visual immediacy present on YouTube. For evidence of the elevation of the viewer's importance we turn to another example, the first of the CNN debates sponsored by YouTube.

On July 23, 2007, the network news station CNN conducted the first ever YouTube sponsored television debate. The eight democratic candidates seeking the democratic nomination were live in the TV studio and were asked questions that were previously collected by the campaign organizers on the YouTube website. ${ }^{11}$ The candidates were thus given questions from actual Americans on the issues most important to them. As Finnegan and Gold (2007) of the LA Times report:

With its earnest input from average Americans in their homes, Monday's program marked a significant turn in the evolution of presidential debates, a Web-era update of the 'town hall' format that first gained favor among political strategists in 1992. The home settings of the videos personalized many questions, including one on healthcare from a woman with breast cancer who removed her wig to display the baldness wrought by chemotherapy.

(Finnegan and Gold 2007)

The result of the program, as the article reports, was that the average voter became the star of the show as opposed to network heads, pundits, or even candidates. Not only were the viewers heard by the candidates, they became prime-time television personalities. It is evident in this case that YouTube is perceived as providing viewers with the opportunity to engage with the candidates.

However, it should be stressed that only 38 of the 3,027 clips were chosen to be broadcast live during the debate. This means of course that the elevated viewer status is deceptive in that $\mathrm{CNN}$, as the organization which chose the questions, is the more powerful player. ${ }^{12}$ In the same way as CNN could choose the questions to be discussed, Obama and Clinton had the power ${ }^{13}$ to decide to which of the many reactions, evoked by their CONVERSATION clips, they would respond. The issue of power will be taken up again in Section 5 . 


\section{Currency: Linguistic topicality and coherence}

Now that we have discussed how the candidates and the media have perpetuated the VIDEO EXHCHANGE IS CONVERSATION metaphor, we can turn to an analysis of the restrictions imposed by medium and metaphor and the consequences for linguistic choices. These restrictions are not necessarily negative or positive in nature, but they encourage or discourage certain types of relational work and identity construction. We would thus like to stress that the technical restrictions that we discuss should not be read as 'computer determinism' (Baym 1995: 139) or 'technical determinism' (Androutsopoulos 2006: 421). In other words, we acknowledge that the candidates are able to exploit the medium's technical restrictions as well as being constrained by them. The two main restrictions caused by the medium are currency (i.e., topicality and coherence) and asynchronicity (discussed in Section 5). We will elaborate on how the VIDEO EXHCHANGE IS CONVERSATION metaphor works alongside these technical medium restrictions in the following sections.

The first restriction of posting videos on YouTube revolves around currency, specifically with respect to topicality and coherence. Topicality means that the video will only be relevant as a current event when it is first released and before it becomes common knowledge that the candidates are both running presidential campaigns. The second aspect is coherence in the sense of archiving. Although the video will not maintain its currency, it will stay posted on YouTube and will remain available online unless removed by the user, flagged by enough people as inappropriate, or deemed in violation of copyright. However, since videos may be shared rapidly, it would be nearly impossible for the user to remove all versions of the video. At the time of writing, ten months after the release of the videos, they are still posted on YouTube. Any relational work the candidate engages in has to consider these factors, especially when the intention is one of persuasion.

\subsection{Topicality}

Both candidates highlight the currency of their videos within the first four lines. They do so by using charged words, or words which can be called boosting phrases (cf. Holmes 1995; Locher 2006b: 119); that is, they intend to add weight to the utterance, but they are not intended to be face-threatening in this case. Obama (2007a) provides the first example:

(3) $\mathrm{O}: 1$ as many of you ^know over the last few months I've been thinking hard about my plans for two thousand and eight.

2 running for the presidency is a profound 'decision. 
By line (2), less than ten seconds into the video, Obama uses the phrases running for the presidency and profound decision. In doing so, he not only makes the video a current event within its time, he also stresses that this decision is based on serious consideration. Clinton (2007a) follows suit:

(4) $\mathrm{C}: 1$

'I announced today that I'm forming a 'presidential exploratory committee.

2 'I'm not just starting a campaign though I'm beginning a conversation.

3 with ^you.

4 with ^America.

5 because we ^all need to be part of the 'discussion if we're ^all going to be part of the 'solution.

6 and 'all of us `have to be part of the solution.

Clinton mentions presidential exploratory committee (line 1) and starting a campaign (line 2). These phrases boost the immediate relevance of the video and provide the viewer with a reason to engage. In addition, Clinton verbalizes the VIDEO EXCHANGE IS CONVERSATION metaphor by line (3), and thereby already attempts to bond with the viewer by explaining that he/she is now in a conversation with Clinton and emphasizing that this is just the beginning of that conversation.

\subsection{Coherence}

Though the videos will not stay current, they will still remain available online. This means that whatever the candidate mentions in the video must remain coherent with whatever he/she will say and/or do in the future (but see our previous comments above on the possibility of removing clips). This is a new restriction presented by exchanging videos in the sense that the general public, as opposed to just media outlets, now have direct access to the footage. If a candidate says he/she will do something and does not follow through, his/her face and credibility will be severely threatened. This makes the future face-threatening to the candidates, so they are forced into relational work which will mitigate the threat. This manifests itself linguistically partially through hedging but mostly through a unique form of projecting upon the audience, a combination of boosting and praising which makes the viewer the active agent of future events rather than the candidate. This is best explained through examples, first beginning with Obama's (2007a) video:

(5) O: 12 so I've spent some time ^thinking about how I could best 'advance the cause of 'change and 'progress,

13 that we so ^desperately need. 
The modal verb could in line (12) serves as a hedge in this case, one which separates him from specifically committing to advancing the cause of change and progress. He uses a similar technique in excerpt (6):

(6) O: 55 for the next several 'weeks I'm gonna ^talk with people from around the country.

56 listening and learning ${ }^{\wedge}$ more.

57 about the challenges we face as a nation,

58 the opportunities that lie 'before us.

59 and the 'role that a presidential campaign 'might play,

In line (59), Obama separates himself from a full commitment to a presidential campaign with an indefinite article and the emphasis on the modal verb might. This way, should he choose not to begin a campaign, he is not obligated by any statements within the video.

Excerpt (6) also presents the use of the VIDEO EXCHANGE IS CONVERSATION metaphor as a mitigation strategy. As Obama says in lines (55) to (59), he will talk with people. and they will tell him about the challenges the nation faces. In other words, the responsibility of future change lies very much in the hands of the people to whom he will talk. This is better exemplified in extract (7):

(7) O: $50 \quad$ I have great ^faith and 'hope about the 'future.

51 because I believe in 'you.

Here Obama specifically references the future, but he places the responsibility for the future in the hands of the viewer. This strategy goes hand in hand with his face-enhancing of the viewer through praise, '[s]ince highlighting something positive about an addressee, i.e., complimenting him or her, also necessarily reflects on the relationship that you have or wish to create and shape, praise is a manifestation of relational work' (Locher 2006b: 122). The statement I believe in you (line 51) is a powerful piece of face-enhancing relational work which, in this case, not only helps create the relationship between Obama and the viewer; it also shifts some of Obama's responsibility for future events on the viewer. This example is a key to understanding how the medium, the metaphor, and relational work are all intertwined. Obama praises the viewer to transfer responsibility for future events, as the medium makes accepting responsibility for the future a face-threatening act. Therefore, he relies on the VIDEO EXCHANGE IS CONVERSATION metaphor as a mitigation strategy. If he and the viewer are in a casual, balanced conversation, then the viewer is in a position to adopt responsibility for the future as well. An example from Clinton (2007a) helps to elaborate this point: 
(8) C: 5 because we ^all need to be part of the 'discussion if we're ^all going to be part of the 'solution.

Example (8), one of Clinton's few references to the future, illustrates the same idea: the audience members are praised as necessary to solving the country's problems. This strategy is aimed at saving Clinton's face by avoiding claims about her role in the future. An emphasis on the viewer's role detracts from the candidates and saves Clinton's and Obama's faces and gives a semblance of empowering the viewer.

\section{Asynchronicity and identity construction}

While CONVERSATION implies synchronous interaction, the medium YouTube is asynchronous. This fact causes tensions and results in the specific linguistic construction of a viewer and a candidate identity as conversants. Before providing our definition of identity, we would briefly like to point to the candidates' engagement in a discursive practice. Although there is no synchronic face-to-face contact through YouTube, the practice of engaging in the video exchange is a practice which helps construct the identity of the user, much as participating in school functions helped construct Jock identity and cruising the streets of Detroit helped construct Burnout identity in Eckert's (2000) study of Communities of Practice $^{14}$ in a Detroit high school. In fact, the act of posting videos on YouTube itself already constructs identity, since the candidates engage in a discursive practice which, for better or for worse, sees them position themselves as users of the new medium in an attempt to bond with the viewer. Without a word spoken, the candidates begin constructing their identities. However, this constitutes only the first step in identity construction. Our primary focus here is the way in which the candidates construct their own and the viewer's identities and how this is influenced by the asynchronicity of YouTube and the VIDEO EXCHANGE IS CONVERSATION metaphor.

\subsection{Constructing the candidates' identities}

Identity is a very difficult concept to define. We follow Mendoza-Denton's (2001: 489-490) definition, assuming that 'speakers' identities are not a determinate given, but [are] open to transformation, contextually ${ }^{[15]}$ derived, and emergent in interaction' (cf. also Bucholtz and Hall 2005; Locher 2008). Identity, much like the notion of face mentioned earlier, will be fluid in a given interaction and is negotiated constantly. From this perspective, we may analyze the ways in which the candidates develop their own identities with relational work while keeping in mind the context of the medium. 
The asynchronous nature of YouTube allows the candidates to produce carefully planned rhetorical pieces; in this sense the candidates are exploiting the possibilities of this medium. Both Clinton and Obama wish to portray themselves as worthy of the viewer's vote. In other words, the candidates construct their identities as suitably presidential. Throughout their campaigns, each must maintain the credibility of someone who will take charge and make difficult decisions. It is here that the primary dilemma of the VIDEO EXCHANGE IS CONVERSATION metaphor presents itself to the candidates. They desire to portray themselves as 'above the common politician' in running for the presidency. However, this desire creates a tension with the VIDEO EXCHANGE IS CONVERSATION metaphor, as the metaphorical entailments of bonding suggest a more inclusive and personal relationship with the non-politician viewer. In other words, a difference between the conversational partners emerges. This could potentially work against the candidates' intentions. It therefore constitutes a potentially face-threatening act to the candidates.

Perhaps the most interesting aspect of this FTA is that both candidates mitigate it by linguistically creating an in-group/out-group dichotomy. First consider extract (9) from Obama's (2007a) video:

(9) O: 25 but challenging as they are it's not the 'magnitude of our problems that concerns me the ${ }^{\wedge}$ most.

26 it's the 'smallness of our 'politics.

27 America's faced big problems before.

28 but today our leaders in Washington seem incapable,

29 of working together in a 'practical,

30 'common-sense way.

31 politics has become so 'bitter and 'partisan,

32 so gummed up by 'money and 'influence,

33 that we can't tackle the 'big 'problems,

34 that 'demand solutions.

35 and that's what we have to change ^first.

36 we have to change our 'politics.

Obama strategically replaces the second person you with the inclusive pronoun we and the inclusive possessive pronoun our. In lines (28) to (30), he creates a diametric opposition between himself and the viewer on the one hand versus the leaders in Washington on the other. The catch here is that, as a Senator, Obama is a leader in Washington, too. To separate himself in this manner is thus peculiar in the sense that it evokes the question: How can he be expected to lead if he does not take responsibility for being a part of the governmental body which does the leading? He solves this dilemma by creating an in-group/out-group opposition, specifically by switching to the inclusive pronouns we and our whenever mentioning a force which he depicts as negative. By doing so, 
Obama places himself in the group being victimized along with the viewer. By including himself as a victim of negative agents alongside the viewer, he effectively negates any negative associations with Washington. In other words, he constructs his identity as someone who is also affected by the adversities in America's political environment. In this sense, his purpose is to bond with the viewer. In contrast, he maintains his distance as a political leader by returning to the second person you (line 40, Appendix). One aspect of his identity is thus his shared victimhood with the viewer, while another is his independence from the viewer. His construction of identity, in this way, is one of exclusion in the sense that he is neither part of the negative politics nor is he just a viewer. As the speaker able to direct and control the conversation, he presents himself as dominant (presidential) within the interaction. Here is another example of inclusion and exclusion from Obama:
9 as I've read your 'emails and read your 'letters,
10 I've been struck by how ^hungry we ^all 'are.
11 for a ^different kind of politics.

In line (9) Obama separates himself from the viewer. Obviously, the people who sent him these letters and emails felt he was someone with the power to instigate change. He is an authority figure who has received your emails and letters. He thus represents himself as separate from and more powerful than the viewer. Then, when referencing the negative nature of current politics in lines (10) and (11), he bonds with the viewer by announcing that we have been affected by it. This implies that he is a victim, powerless like the viewer. Later he says:
(11) O: 19 many of you have shared with me your 'stories about ^sky-rocketing health care bills.
20 the 'pensions you've lost and your 'struggles to pay for 'college for your 'kids.
21 our continued dependence on oil has put our ^security,
22 and our very 'planet at risk.
23 and we're 'still mired in a tragic and costly war,
24 that should ^never have been waged.

This represents the only passage in which negative concepts are referenced within sentences containing the second person you. Notice, however, what his choice not to use we in this particular case implies: (1) he has no health care bills; he is healthy, (2) he has lost no pensions; he is secure, and (3) he does not struggle to pay for college-aged kids (yet). He cannot exclude himself from dependence upon foreign oil (line 21), so he returns to the pronoun our, which leads him back to his in-group strategy. ${ }^{16}$ He states: 
(12) O: 31 politics has become so ^bitter and 'partisan,

32 so gummed up by ^money and 'influence,

33 that we can't tackle the 'big 'problems,

34 that 'demand solutions.

35 and that's what we have to change 'first.

36 we have to change our ${ }^{\wedge}$ politics.

Politics is presented as the subject in line (31), a subject with no specific agent despite the implicature of current governmental figures. We are hindered by the negative force of politics, unable to solve problems. Therefore, it is our responsibility to change politics. At first, Obama includes himself with the viewer by claiming ownership of our politics in line (36). Then he goes on:

(13) $0: 39$ this won't happen by ^itself.

40 change in our politics can only come from `you.

These lines eloquently sum up the message sent through Obama's use of pronouns. In lines (31) to (36) above, he is a victim of modern politics alongside the viewer, even to the point of admitting that he must play a role along with the viewer in changing politics. Then, in lines (39) and (40), he distinctly separates himself by using you and placing the responsibility of change upon the viewer. He is not only a victim of the negative powers that be, but also separate from the viewer. Though these may seem like a series of contradictory statements, that is not the overall effect. In the end, Obama carves himself a niche in the interaction: an authority figure separate from negative politics and a victimized citizen separate from the viewer. These are the ways in which he is presidential. His identity is constructed through his disassociation with both the viewer and Washington.

Clinton creates an in-group/out-group dichotomy by focusing on the VIDEO EXCHANGE IS CONVERSATION metaphor. To return to the first lines of Clinton's (2007a) video:

(14) $\mathrm{C}: 1$ I I announced today that I'm forming a 'presidential exploratory committee.

2 'I'm not just starting a campaign though I'm beginning a conversation.

3 with 'you.

4 with ^America.

From the first lines, Clinton makes it clear that her campaign and the video exchange are all part of a conversation with the viewer. By using the pronoun you and the term America, she addresses both the viewer as an individual and the viewer as a member of a collective. ${ }^{17}$ This positions her as the conversation starter and as worthy of conducting a conversa- 
tion with an entire nation, a position suited normally only to someone of significant status. This means that she has already established her exclusion from the audience and her status as presidential. Her next task, much like Obama, is then to separate herself and her audience from the present political structure:

(15) C: 12 you know after ^six years of 'George Bush,

13 it is 'time to renew the promise of America.

In lines (12) to (13) she distances America from incumbent president George W. Bush. Bush is clearly not a part of the conversation nor is he contributing to the promise of America. She elaborates this in (16):

(16) C: 27 so let's ^talk.

28 let's 'chat.

29 let's start a ^dialog about ^your ideas and 'mine.

30 because the conversation in Washington has been just a little 'onesided lately don't you 'think?

31 and we can ^all see how well ^that works.

In line (31) Clinton uses irony as part of her identity construction. In this way she can be critical, but with a sense of humor. Such irony appears to be absent from Obama's video. The metonymic reference to Washington in line (30) achieves three effects: (1) separating Clinton from the present political structure, (2) separating the audience from the political structure, and (3) extending the VIDEO EXCHANGE IS CONVERSATION metaphor in such a way that Clinton and the audience are in the correct conversation and Washington is conducting an inaccessible, unfruitful conversation. In fact, as members of the conversation with Clinton, the audience is invited to criticize the other conversation in lines (30) and (31). Much like Obama, Clinton again separates herself from the political structure, a potentially face-threatening move seeing that she is a Senator from New York and as such part of this structure. However, this seems counterbalanced by the in-group/out-group technique which, exactly as with Obama, simultaneously connects her with the audience and removes her from the audience.

These methods of exclusion for identity construction all function by virtue of the VIDEO EXCHANGE IS CONVERSATION metaphor. Both candidates, by choosing to use this metaphor, place themselves in a vulnerable or face-threatening position. They compensate through the linguistic techniques listed above which allow them to mitigate any threat to face while simultaneously creating a niche for themselves within the conversation in which they occupy a position of relative prestige, a position they hope will lead the viewer to vote for them in the upcoming election. 
Both candidates create an in-group/out-group dynamic, one which is essential to their own identities. Dealing with in-group/out-group language has already provided evidence that the medium (or lack of direct face-to-face contact) has necessitated another element of construction, the construction of the viewer's identity.

\subsection{Constructing the viewer's identity}

In constructing their identities, the candidates are congruently constructing the identity of the viewer. The candidate and viewer do not interact in the traditional face-to-face sense during the video exchange. Therefore, the viewer cannot contribute to the relational work in at least the first video of the 'conversation'. This is a restriction imposed by the medium's asynchronicity. The presence of an addressee, because of the metaphor, must also be reflected within the first video, otherwise it is not a conversation. This is the restriction imposed by the metaphor. The candidates use these restrictions to their advantage in the sense that they may define their ideal viewers. Using the candidates' linguistic choices as a guide, we have paraphrased some of the key ways in which the viewer's identity is outlined and defined within each video:

\section{Obama Viewer}

You are hungry for a different kind of politics. (lines 10-11)

You are a victim of the changes and problems currently affecting America. (lines 14-24)

You are not a leader in Washington. (lines 28-34)

You have the power to change politics. (line 35-43)

You are someone in whom I believe. (line 51)

You are the first person I wanted to tell I might be running for president. (line 52)

You are someone who supports me. (lines 67-70)

\section{Clinton Viewer}

You are an American. (lines 3-4)

You are important enough for me to converse with you. (lines 3, 6)

You must discuss/respond because you must be a part of the solution. (line 6, 7, 11, 27-29)

You are not involved in the conversation in the White House. (line 30) You are very interesting. (line 36)

In both clips, the viewer is portrayed as a victim of the American government. The candidates make it clear that the politics in Washington are presently unacceptable and that the viewer is not one of the people in- 
volved in these politics. However, neither candidate provides a way for the viewer to combat this problem. Obama believes in the viewer, and that only he/she can change politics. Clinton thinks that the viewer has many interesting things to say and wants him/her to be part of the discussion to change the status quo. But neither candidate gives a concrete indication as to how the viewer can propagate change - not even an explicit reference to voting. In the end, it is enough simply to watch the video, despite the fact that the viewer has the possibility of posting her/ his own clips or text comments.

Nevertheless, both candidates construct her/his viewer as empowered in the sense that they are conversants with the presidential candidates. The question which would require empirical research is whether or not such identity construction actually has an effect on the viewer. Effective or not, the identity construction caused by the metaphor leads to an inevitable consequence: the candidates must continue the conversation. But the candidates can hardly respond to every posting. ${ }^{18}$ In fact, in one of Obama's (2007c) following videos, entitled Dinner with Obama (June 12, 2007), he admits that he has been on the YouTube website only once. In other words, the VIDEO EXCHANGE IS CONVERSATION metaphor requires that the candidates maintain an online, video exchanging presence. To not do so would undermine their metaphor. This makes both the YouTube medium and the VIDEO EXCHANGE Is CONVERSATION metaphor particularly noteworthy, in that they necessitate further action from the candidates.

\section{Continuing the conversation}

From this perspective, the VIDEO EXCHANGE IS CONVERSATION metaphor stretches beyond the boundaries of the individual videos. Each video serves as part of a meta-conversation over disparate space and time. This is possible only with the new technology at hand. Each video as a whole serves as an element of the wider interaction taking place between each candidate and the viewer. This is an important concept, as it sheds light on the ways future analysis of such media might be pursued. Evidence to support this claim is already available. Both Obama and Clinton have continued their conversations with several videos. However, Table 1 shows that of the 89 contributions posted by Hillary Clinton on YouTube between January 16 and November 7, 2007, only twelve make explicit use of the conversation metaphor. In Obama's case this number is even smaller, with only eight clips. This might point to the challenges of adhering to the conversation metaphor. 
Table 1. The type of contributions to YouTube by Clinton and Obama (January 16-November 7,2007 ).

\begin{tabular}{lll}
\hline Type & $\begin{array}{l}\text { Hillary Clinton } \\
\text { source: } \\
\text { HillaryClintondotcom } \\
\text { at YouTube }\end{array}$ & $\begin{array}{l}\text { Barack Obama } \\
\text { source: } \\
\text { BarackObamadotcom } \\
\text { at YouTube }\end{array}$ \\
\hline Conversation metaphor: & 12 & 8 \\
Conversation with person(s): & 6 & 14 \\
Debate: & 10 & 4 \\
Public speech: & 29 & 91 \\
Reference to candidate & & 94 \\
$\quad$ (not featuring candidate): & 19 & 28 \\
Television appearance: & 9 & 11 \\
Television spot: & 4 & 250 \\
\hline Total & 89 & \\
\hline
\end{tabular}

The VIDEO EXCHANGE IS CONVERSATION metaphor is a choice, and it is not the only one available to the candidates. Though they must continue the conversation by virtue of the restrictions that they have set for themselves, they may also distance themselves from the metaphor and explore new territories. Their choices will immediately reflect their commitment to the metaphor. That is to say, the commitment to the metaphor may be viewed as a spectrum. A commitment to the metaphor represents the attempt to break through the mediation and come as close as possible to face-to-face interaction. Breaking away from the metaphor represents distancing the viewer from the role of conversant. Interestingly enough, both candidates take diverging paths.

Following her I'm In (Clinton 2007a) video, Clinton (2007b, c, d) hosts a series of online 'chats' all entitled Let the Conversation Begin. In three half-hour videos she answers questions which were posted on her website blog by individuals in the U.S. nation. Though the viewer is given the impression that this is a representative sample, this is misleading. Clinton can be assumed to have carefully selected the questions to answer and in this she creates an identity for the people who 'converse' with her not individually but as a body. She gives the viewers a voice by allowing her campaign blogger, who is also visually present in the clip, to read out their questions. This could be interpreted as an attempt at minimally simulating a conversation situation.

Amidst updates she entitles HillCasts, Clinton (2007e, f) posted her videos I Need Your Advice and Pick My Campaign Song: Round 2. In the videos she asks the viewer to send in suggestions for her campaign song. To announce the song finalist, Clinton diverges from the VIDEO EXCHANGE IS CONVERSATION metaphor. Rather than an image of her looking into the camera, she presents a narrative. The narrative is a parody of 
the finale of the popular TV series The Sopranos (Clinton 2007g). In the video, she walks into a café followed shortly after by her husband Bill (ironically, comparing them to a mobster family) and ends the clip as a cliffhanger announcing that the winning song can be found on her website. Clinton's intention is less likely to liken herself to a crime lord than to evoke the cliffhanger quality of the final Sopranos episode. At the same time, she taps into specific American pop cultural knowledge, namely that of the premium channel $\mathrm{HBO},{ }^{19}$ which effectively creates another bond with her viewer community. This video seems to drop the VIDEO EXCHANGE IS CONVERSATION metaphor and draw upon the much more common television and film genre of fictional narratives. The viewer no longer plays a role or has responsibility, but rather can sit back and watch the action unfold.

Obama, on the other hand, takes a very different route. His next video entitled Dinner with Barack Obama (Obama 2007b) features him, again looking into the camera, explaining that he will invite four people who contribute one hundred dollars or less to his campaign to dinner with him in Washington in order for them to discuss political issues on a faceto-face basis. His intentions might have been to break the barriers of the mediated world and extend the VIDEO EXCHANGE Is CONVERSATION metaphor to reality. Naturally, Obama's (2007c) next video is of the dinner itself, again entitled Dinner with Barack Obama. The video features him sitting at a table with four Americans selected on the basis of their submitted videos and small donations. Obama's commitment to the VIDEO EXCHANGE IS CONVERSATION metaphor simultaneously reflects his adoption of YouTube as a persuasive tool, one which gives each user a better opportunity to participate in his campaign. Once again, however, Obama is given the chance to construct the viewer. His aides certainly edited the video, and he or they chose the people who would attend the dinner. In addition, though the conversants have been elevated to the status of dinner guests, their power adds up to little more than 'able to literally speak' with the candidate. In the end, just like Clinton, his dinner video also breaks away from the VIDEO EXCHANGE IS CONVERSATION metaphor, since the dinner unfolds as if it were a narrative and the viewer is no longer constructed as a conversant in the addressee position. ${ }^{20}$

Obama seems to be breaking through the confinements of asynchronous conversation, but his attempt to do so might also betray the original metaphor. Obama constructs the viewer as a conversant, but then only allows those who pay to interact with him on a face-to-face basis. Clinton, on the other hand, becomes a star, one who appears on the screen as an actor whose narrative is important enough for us to watch. In this sense, the viewer is no longer asked to engage in a conversation. 
We should stress of course that the candidates' campaigns are not over at the time of writing and that they have the opportunity to reuse the metaphor whenever they wish to create coherence with the beginnings of their campaigns.

\section{Conclusions}

As we write, Barack Obama and Hillary Clinton remain in the race for the Democratic presidential candidacy in 2008. This paper examines but one aspect in their appeal to voters, albeit an important one. Video exchanging on popular websites such as YouTube is a new technology. More importantly, these initial videos have sparked off a series of politically-oriented YouTube videos and threads, both from candidates and voters alike. Following the release of Obama's and Clinton's videos, there is a YouTube page, entitled You Choose '08, encouraging the comparison of all the candidates, some of whom also employ the CONVERSATION metaphor and thus contribute to its perpetuation. ${ }^{21}$ Our primary focus has been the VIDEO EXCHANGE IS CONVERSATION metaphor, the metaphor which both candidates use as means to simulate face-to-face interaction. It is a conceptual, multimodal metaphor which draws upon the source domain of CONVERSATION and relies upon the spoken and visual modes. Specifically, we focused on the restrictions of the medium (i.e., video exchanging online) and the metaphor, as well as on the consequences that these restrictions have on relational work between addresser and addressee. This discussion features the restrictions of currency (topicality and coherence) and asynchronicity, which structure the nature of the pseudo-dialogic interaction. Medium and metaphor necessitate a continuation of the conversation, the construction of the viewer identity, and shape the nature of the candidates' identities. In addition, they prove to be face-threatening while also providing opportunities for face-saving and face-enhancing.

The VIDEO EXCHANGE IS CONVERSATION metaphor discussed in this paper marks a new direction in the study of online language, one which highlights both the importance of media restrictions and the role of conceptualization. Our cognitive approach, supported by linguistic evidence, demonstrates the intricacies of online interaction and the fundamental need to consider multiple modes. For, as we have demonstrated, all of these modes play a role in the relational work between sender and recipient. Both medium and metaphor influence how the candidates address and engage the viewer, how they refer to the future, how they construct themselves and their roles within the political structure, and how the viewer should interpret the interaction and situate the speech event within the larger campaign framework. This study is particularly relevant 
in its consideration of politically-motivated exchanges, as it demonstrates how political leaders may use a new form of communication such as YouTube to harness concepts for rhetorical purposes. The concept of CONVERSATION allows the candidates to create the illusion of connecting with the viewer on an equal level, and this bond helps elevate the viewer's status. As we have seen, television media outlets have perpetuated this elevated role, making YouTube users stars on prime-time television. The implication in elevating the viewer, of course, is that he/she plays a more significant role in the democratic process. This inference is worth examining.

In Postman's ([1985] 2005) Amusing Ourselves to Death, he provides a critical account of our culture's 'media-metaphor shift' from one living in the Age of Typography to one consumed by the Age of Television. He describes his thesis as a modification of McLuhan's (1964) famous idiom 'the medium is the message'. Instead, Postman ([1985] 2005) argues that the 'medium is the metaphor':

A message denotes a specific, concrete statement about the world. But the forms of our media, including the symbols through which they permit conversation, do not make such statements. They are rather like metaphors, working by unobtrusive but powerful implication to enforce their special definitions of reality. Whether we are experiencing the world through the lens of speech or the printed word or the television camera, our media-metaphors classify the world for us, sequence it, frame it, enlarge it, reduce it, color it, argue a case for what the world is like.

(Postman [1985] 2005: 10)

Postman's thesis serves as a reminder that when we use new media, such as video exchanging online, our interpretation of the larger, cultural interaction is simultaneously shaped. His argument centers around television, and how short clips and emotional appeals found on television lead to a culture that no longer rationalizes in the ways encouraged by the printed word. The same may be applied to video exchanging, as it allows the creation of an illusion of immediate, face-to-face conversation. The restrictions upon which this paper focused highlight this point exactly. When candidates use this medium, and their goals are persuasion and placing the viewer in a specific role, they are also shaping the ways a viewer might interpret his/her role within the democracy. This is beneficial, as video exchanging allows an entirely new type of public forum, one in which viewers from across the nation may engage in public debate. It is also misleading, however, as viewers have very limited to no contact with the candidates. Ultimately, the conversation between candidate and viewer is very one-sided. 
Future studies in the field are limitless. The application of cognitive linguistics to the visual realm might be an intimidating step, but it is a potentially fruitful one, as this paper has revealed. Understanding the role of medium and metaphor online is a key to understanding language online. The connection between them is too intertwined to separate, too important to omit.

University of Berne

University of Basle

\section{Appendices}

Transcription conventions (based on Du Bois et al. 1992)

${ }^{\wedge}$ word primary stress

'word secondary stress

, . ? continuing, falling, raising intonation at end of tone unit

.. pause

with a-- truncated utterance

CU close up

MS medium shot

\section{Transcripts}

A: Barack Obama Video: My Plans for 2008

Posted: January 16, 2007

From: BarackObamadotcom

FADE IN:

The background is out of focus, but Barack Obama sits in what appears to be a living room area. An orange-colored picture hangs on the wall on the upper left corner of the screen. The upper right corner reveals a window which allows in natural light. It is daytime. A few feet in front of the window there appears to be a railing, which creates a series of horizontal lines on the right side of the screen. The 'set' is professionally lit. (see screenshot 1)

\begin{tabular}{|c|c|c|c|}
\hline Time & '\# & Linguistic & Visual \\
\hline 0:01 & 1 & $\begin{array}{l}\text { as many of you `know over the last few } \\
\text { months I've been thinking `hard about } \\
\text { my plans for two thousand and ^eight. } \\
\text { ^running for the presidency is a } \\
\text { 'profound 'decision. }\end{array}$ & $\begin{array}{l}\text { MS: Senator Barack } \\
\text { Obama sits facing the } \\
\text { camera, his eyes directly } \\
\text { into the lens. He wears a } \\
\text { dark grey business jacket } \\
\text { with a light blue collared } \\
\text { shirt, the top button of } \\
\text { which is unbuttoned. His } \\
\text { hands enter the bottom of } \\
\text { the screen in a controlled } \\
\text { upldown motion } \\
\text { throughout the clip. }\end{array}$ \\
\hline
\end{tabular}




\begin{tabular}{|c|c|c|c|}
\hline Time & $\#$ & Linguistic & Visual \\
\hline $0: 11$ & 3 & $\begin{array}{l}\text { a 'decision no one should make on the } \\
\text { basis of ^media 'hype or personal } \\
\text { 'ambition 'alone, }\end{array}$ & $\begin{array}{l}\text { Circular hand motions on } \\
\text { 'media hype'. }\end{array}$ \\
\hline \multirow[t]{6}{*}{$0: 17$} & 4 & $\begin{array}{l}\text { and so before I committed 'myself and } \\
\text { my 'family to this race. }\end{array}$ & $\begin{array}{l}\text { One pronounced hand } \\
\text { motions. }\end{array}$ \\
\hline & 5 & $\begin{array}{l}\text { I wanted to be sure that this was right } \\
\text { for ^us. }\end{array}$ & \\
\hline & 6 & $\begin{array}{l}\text { And more ^importantly ^right for the } \\
\text { country. }\end{array}$ & \\
\hline & 7 & $\begin{array}{l}\text { I certainly didn't expect to 'find myself in } \\
\text { this position a year ago. }\end{array}$ & \\
\hline & 8 & $\begin{array}{l}\text { but as I've spoken to 'many of you in } \\
\text { my travels across the `states these past } \\
\text { months. }\end{array}$ & \\
\hline & 9 & $\begin{array}{l}\text { as I've read your 'emails and read your } \\
\text { 'letters, }\end{array}$ & \\
\hline \multirow[t]{2}{*}{$0: 33$} & 10 & $\begin{array}{l}\text { I've been struck by how ^hungry we ^all } \\
\text { 'are. }\end{array}$ & $\begin{array}{l}\text { One pronounced hand } \\
\text { motion with 'hungry'. }\end{array}$ \\
\hline & 11 & For a ^different kind of politics. & \\
\hline \multirow[t]{5}{*}{$0: 36$} & 12 & $\begin{array}{l}\text { so I've spent some time 'thinking about } \\
\text { how I could best 'advance the cause of } \\
\text { 'change and 'progress, }\end{array}$ & Circular hand motions. \\
\hline & 13 & that we so ^desperately need. & \\
\hline & 14 & $\begin{array}{l}\text { the decisions that have been 'made in } \\
\text { Washington these past six years. }\end{array}$ & \\
\hline & 15 & $\begin{array}{l}\text { And the problems that have been } \\
\text { ignored. }\end{array}$ & \\
\hline & 16 & $\begin{array}{l}\text { have put our country in a 'precarious } \\
\text { 'place. }\end{array}$ & \\
\hline \multirow[t]{2}{*}{$0: 51$} & 17 & Our economy’s changing ^rapidly. & Circular hand motions. \\
\hline & 18 & $\begin{array}{l}\text { And that means profound 'changes for } \\
\text { working 'people. }\end{array}$ & \\
\hline 0:58 & 19 & $\begin{array}{l}\text { many of you have shared with me your } \\
\text { 'stories about 'sky-rocketing health care } \\
\text { bills. }\end{array}$ & $\begin{array}{l}\text { Concerned face; eyebrows } \\
\text { toward one another. }\end{array}$ \\
\hline \multirow[t]{2}{*}{ 1:00 } & 20 & $\begin{array}{l}\text { the 'pensions you've lost and your } \\
\text { 'struggles to pay for 'college for your } \\
\text { 'kids. }\end{array}$ & Circular hand motions. \\
\hline & 21 & $\begin{array}{l}\text { Our continued dependence on oil has put } \\
\text { our 'security, }\end{array}$ & \\
\hline \multirow[t]{3}{*}{ 1:07 } & 22 & And our very 'planet at risk. & $\begin{array}{l}\text { One pronounced hand } \\
\text { motions. }\end{array}$ \\
\hline & 23 & $\begin{array}{l}\text { And we're `still mired in a tragic and } \\
\text { costly war, }\end{array}$ & \\
\hline & 24 & that should ^never have been waged. & \\
\hline \multirow[t]{3}{*}{$1: 17$} & 25 & $\begin{array}{l}\text { but challenging as they are it's not the } \\
\text { 'magnitude of our problems that } \\
\text { concerns me the ^most. }\end{array}$ & $\begin{array}{l}\text { One pronounced hand } \\
\text { motion. }\end{array}$ \\
\hline & 26 & it's the ^smallness of our 'politics. & \\
\hline & 27 & America's faced big problems before. & \\
\hline
\end{tabular}




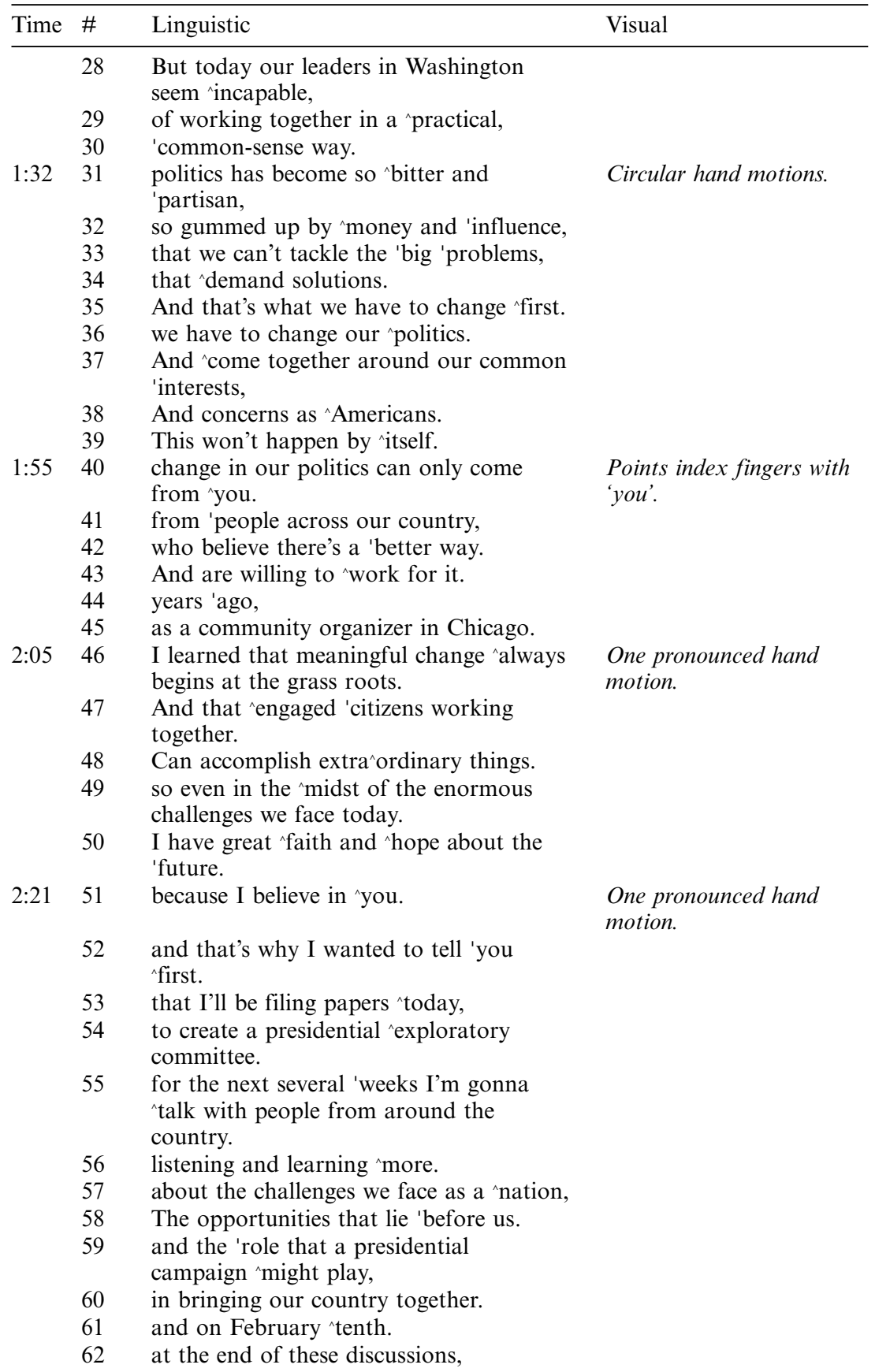




\begin{tabular}{|c|c|c|c|}
\hline Time & $\#$ & Linguistic & Visual \\
\hline & 63 & and in my home state of 'Illinois. & \\
\hline & 64 & I'll share my plans with my 'friends, & \\
\hline & 65 & 'neighbors, & \\
\hline & 66 & and fellow 'Americans. & \\
\hline \multirow[t]{4}{*}{$2: 57$} & 67 & $\begin{array}{l}\text { In the meantime I want to thank }{ }^{\wedge} \text { all of } \\
\text { you for your }{ }^{\wedge} \text { time, }\end{array}$ & $\begin{array}{l}\text { Spread hand motions on } \\
\text { 'all'. }\end{array}$ \\
\hline & 68 & your 'suggestions, & \\
\hline & 69 & your 'encouragement, & \\
\hline & 70 & and your 'prayers. & \\
\hline \multirow[t]{6}{*}{ 3:02 } & 71 & and I look forward to continuing our & White text: PAID FOR \\
\hline & & 'conversation. & BY THE OBAMA \\
\hline & & & EXPLORATORY \\
\hline & & & COMMITTEE. \\
\hline & 72 & in the 'weeks and 'months to come. & \\
\hline & 73 & & FADE OUT \\
\hline
\end{tabular}

\section{B: Hillary Clinton Video: I'm In}

Posted: January 22, 2007

From: hillaryclintondotcom

\section{FADE IN:}

Background: Hillary Clinton clearly sits in a living room with a couch. In the upper left hand corner is a lamp sitting on a small table which provides a glowing orange light. The couch on which she sits is tan with plant patterns, and to her right. Just behind her back is a large white pillow with flower patterns. In the right half of the screen, at the very back of the wall is a door leading outside, where a small patio is visible as well as an upkept lawn with small trees. It is daytime. Inside there is a wooden table with a piano chair. On the table is a bouquet of pink roses as well as four pictures of what appear to be family members. (see screenshot 2)

\begin{tabular}{lll}
\hline Time & $\#$ & Linguistic \\
\hline $0: 01$ & 1 & $\begin{array}{l}\text { I I announced today that I'm forming a } \\
\text { 'presidential exploratory committee. }\end{array}$
\end{tabular}

2 I'm not just starting a campaign though

Visual

MS: (Camera pans left until 0:07, where it stops with her in center.) Hillary Clinton sits with hands folded in lap on the couch facing directly into the camera. She wears a black shirt and black pants with a deep red jacket.

$$
\begin{array}{lll}
0: 09 & 3 & \begin{array}{l}
\text { I'm beginning a } \\
\text { with ^you. }
\end{array} \\
& 4 & \text { with ^America. }
\end{array}
$$




\begin{tabular}{|c|c|c|c|}
\hline Time & $\#$ & Linguistic & Visual \\
\hline $0: 12$ & 5 & $\begin{array}{l}\text { because we all need to be part of the } \\
\text { 'discussion if we're ^all going to be part } \\
\text { of the 'solution. }\end{array}$ & $\begin{array}{l}\text { (Camera pans slowly to } \\
\text { the left.) First hand } \\
\text { movement; both hands. }\end{array}$ \\
\hline $0: 17$ & 6 & $\begin{array}{l}\text { and ^all of us 'have to be part of the } \\
\text { solution. }\end{array}$ & $\begin{array}{l}\text { Leans forward and sets } \\
\text { hands back on lap. }\end{array}$ \\
\hline $0: 19$ & 7 & $\begin{array}{l}\text { let's 'talk about how to bring the 'right } \\
\text { end to the war in Iraq. } \\
\text { and to restore respect for 'America } \\
\text { around the world. }\end{array}$ & $C U:$ (Camera pans left.) \\
\hline $\begin{array}{l}0: 26 \\
0: 28\end{array}$ & 9 & $\begin{array}{l}{ }^{\wedge} \text { How to 'make us 'energy 'independent } \\
\text { and 'free of foreign oil. }\end{array}$ & $\begin{array}{l}\text { (Camera pans right.) } \\
\text { Leans forward (camera } \\
\text { pans right to } \\
\text { accommodate movement.) }\end{array}$ \\
\hline & 10 & $\begin{array}{l}\text { how to end the deficits that threaten } \\
\text { social security and 'medicare. }\end{array}$ & \\
\hline $0: 33$ & 11 & $\begin{array}{l}\text { and let's 'definitely talk about how 'every } \\
\text { 'American can have quality affordable } \\
\text { health care. }\end{array}$ & (Camera pans left.) \\
\hline $0: 39$ & 12 & $\begin{array}{l}\text { you know after ^six years of 'George } \\
\text { Bush, }\end{array}$ & $\begin{array}{l}\text { Moves right arm to rest } \\
\text { on pillow. }\end{array}$ \\
\hline $0: 44$ & 13 & $\begin{array}{l}\text { it is time to renew the promise of } \\
\text { America. } \\
\text { 'our basic bargain, }\end{array}$ & (Camera pans right.) \\
\hline $0: 47$ & 15 & $\begin{array}{l}\text { that no 'matter }{ }^{\wedge} \text { who you are or }{ }^{\wedge} \text { where } \\
\text { you live, } \\
\text { if you work hard and play by the rules, }\end{array}$ & $\begin{array}{l}\text { Hand movement enters } \\
\text { lower screen. }\end{array}$ \\
\hline $0: 51$ & 17 & $\begin{array}{l}\text { you can build a good life for yourself } \\
\text { and your family. }\end{array}$ & (Camera pans left.) \\
\hline $0: 53$ & 18 & $\begin{array}{l}\text { I grew up in a 'middle class family in the } \\
\text { 'middle of America, }\end{array}$ & $\begin{array}{l}\text { MS: (Camera pans left.) } \\
\text { Moves right arm to rest } \\
\text { on pillow (again). } \\
\text { Large hand movement. }\end{array}$ \\
\hline & 19 & and we ${ }^{\wedge}$ believed in that promise. & \\
\hline 1:01 & $\begin{array}{l}20 \\
21\end{array}$ & $\begin{array}{l}\text { ^I still do. } \\
\text { I've spent my 'entire life trying to make } \\
\text { } \text { good on it. }\end{array}$ & (Camera pans right.) \\
\hline & 22 & $\begin{array}{l}\text { whether it was fighting for 'women's } \\
\text { basic rights or 'children's basic health } \\
\text { care. }\end{array}$ & \\
\hline 1:09 & $\begin{array}{l}23 \\
24\end{array}$ & $\begin{array}{l}\text { protecting our 'social security, } \\
\text { Or protecting 'our soldiers. }\end{array}$ & (Camera pans left.) \\
\hline $1: 11$ & 25 & it’s a kind of ‘basic 'bargain. & $\begin{array}{l}\text { One hand movement, } \\
\text { makes a fist. }\end{array}$ \\
\hline $1: 16$ & $\begin{array}{l}26 \\
27\end{array}$ & $\begin{array}{l}\text { and we've 'got to keep up 'our end. } \\
\text { So let's 'talk. }\end{array}$ & $\begin{array}{l}\text { (Camera pans right.) } \\
\text { Leans forward, removes } \\
\text { arm from rest position, } \\
\text { and holds hands together } \\
\text { on lap. }\end{array}$ \\
\hline
\end{tabular}




\begin{tabular}{|c|c|c|c|}
\hline Time & $\#$ & Linguistic & Visual \\
\hline & 28 & let's 'chat. & \\
\hline & 29 & $\begin{array}{l}\text { let's start a ^dialog about ^your ideas and } \\
\text { 'mine. }\end{array}$ & \\
\hline $1: 22$ & 30 & $\begin{array}{l}\text { because the conversation in Washington } \\
\text { has been just a little `one-sided lately } \\
\text { don't you 'think? }\end{array}$ & (Camera pans left.) \\
\hline $1: 27$ & 31 & and we can all see how well ^that works. & (Camera pans right.) \\
\hline \multirow[t]{2}{*}{$1: 29$} & 32 & $\begin{array}{l}\text { and while I 'can't visit 'everyone's living } \\
\text { room, }\end{array}$ & $\begin{array}{l}\text { Hand movement and leans } \\
\text { forward. }\end{array}$ \\
\hline & 33 & I can ${ }^{\wedge}$ try. & \\
\hline $1: 32$ & \multirow[t]{2}{*}{34} & and with a little help from modern & One hand movement. \\
\hline $1: 34$ & & $\begin{array}{l}\text { technology I'll be holding live online } \\
\text { video chats this week ^starting Monday. }\end{array}$ & (Camera pans left.) \\
\hline \multirow[t]{9}{*}{$1: 39$} & 35 & So let the ${ }^{\wedge}$ conversation 'begin. & (Camera pans right.) \\
\hline & & & $\begin{array}{l}\text { Hand movement and leans } \\
\text { forward; prominent, } \\
\text { positive nods. }\end{array}$ \\
\hline & \multirow[t]{2}{*}{36} & \multirow[t]{7}{*}{$\begin{array}{l}\text { I have a 'feeling it's going to be ^very } \\
\text { 'interesting. }\end{array}$} & $\begin{array}{l}\text { FADE OUT TO: Black } \\
\text { screen, with }\end{array}$ \\
\hline & & & HillaryClinton.com, \\
\hline & \multirow{2}{*}{37} & & $\begin{array}{l}\text { PAID FOR BY } \\
\text { HILLARY CLINTON }\end{array}$ \\
\hline & & & FOR \\
\hline & \multirow[t]{3}{*}{38} & & PRESIDENT \\
\hline & & & EXPLORATORY \\
\hline & & & COMMITTEE \\
\hline
\end{tabular}

\section{Notes}

1. We wish to express our gratitude to hillaryclintondotcom and to barackobamadotcom for allowing us to analyze and make use of their video clips. Our thanks also go to Brook Bolander, Matt Kimmich, Richard Watts, and the anonymous reviewers for giving us valuable feedback on earlier versions of this paper.

2. This is our assessment based on the eleven categories provided by YouTube, only one of which addresses News \& Politics. Others include Entertainment, Comedy, How To \& Style, Sports, etc.

3. Of course there is an element of persuasion in all posted videos on YouTube in the sense that people are engaging in a process of self-advertising. The facet of persuasion is also not particular to YouTube alone.

4. We consider immediacy to be so crucial because, for example, exchanges on the telephone or in instant messengers are also referred to as conversations, whereas e-mailing or letter writing still qualify as 'exchanges of ideas' but are less likely to be considered conversations (cf. Section 3).

5. Though the digital age now allows videos to be nothing more than recorded data on a hard drive (as opposed to the magnetic strip onto which videos were formerly recorded), the term videos is still predominantly used, especially on sites such as YouTube. 
6. Goffman borrowed the concept face from Durkheim (1915). For further developments of this concept, cf. Brown and Levinson (1987), Bargiela Chiappini (2003), Arundale (2006).

7. Lakoff and Johnson modify the Argument Is WAR metaphor to include ArguMENT IS STRUGGLE in the 2003 edition of Metaphors We Live By.

8. We are aware of the fact that the VIDEO EXCHANGE and CONVERSATION elements of the metaphor are conceptually closer than perhaps those of the ARGUMENT IS WAR metaphor. However, we still feel that that the immediacy lacking in the video exchange necessitates a metaphorical understanding.

9. The VIDEO EXCHANGE IS CONVERSATION metaphor was of course not invented by the candidates; it is simply exploited by them. YouTube users have already become accustomed to face-to-face mimicry, as any casual visit to the site will reveal. Because of the pervasiveness of this metaphor, the significance of both candidates choosing to use it is not immediately apparent. Though it might seem like common sense to use a video forum as an open-ended political conversation, opting for the VIDEO EXCHANGE IS CONVERSATION metaphor is a paradigmatic choice - and one that fits the possibilities of YouTube nicely.

10. It is interesting that the candidates can use the metaphor without ever getting a response. This would, of course, be very face-threatening to them.

11. The collection of video clips was submitted to YouTube under the heading 'The CNN YouTube Debates'.

12. See http://www.youtube.com/watch?v=4FswauQk_po for the beginning of the CNN debate (accessed on October 29, 2007), which explains the selection procedure.

13. We use the term power here in the sense of $\mathrm{Ng}$ and Bradac's (1993: 3) definition of 'power to', or the positive sense of being able to realize 'personal or collective goals' (cf. Locher 2004).

14. Eckert and McConnell-Ginet (1992: 464, as quoted in Meyerhoff 2002: 527) posit that '[a] community of practice is an aggregate of people who come together around mutual engagement in an endeavor ... practices emerge in the course of this mutual endeavor.'

15. Context does not just include the linguistic environment, but also the physical and metaphorical environments. We do not wish to imply that the visual aspect should be neglected at the expense of the linguistic. Here we agree with Scollon (2001: 4, as quoted in Filliettaz 2005: 100), who deplores the fact that the term context seems to suggest that the other modes of communication are in the background of analysis.

16. An alternative reading of this is that his use of your in lines 19 and 20 has an unselfish and self-effacing effect.

17. In addition, Clinton restricts the number of addressees by making her statements relevant to American viewers, rather than to the potential international audience.

18. In fact, one of the authors sent each candidate an email asking whether or not they take the time to answer video responses. At the time of writing, ten months later, he has received no response, but, much to the chagrin of his inbox, he receives daily campaign updates.

19. In her choice of an HBO series, Clinton goes for a high-profile production rather than a basic cable program such as 'American Idol'.

20. One could of course argue that the clip 'Dinner with Obama' constitutes an interactional turn in the ongoing exchange between the candidate and viewers. In this reading, the format of YouTube itself maintains the illusion of the CONVERSATION metaphor.

21. The site may be found at: http://www.youtube.com/youchoose. 


\section{References}

\section{Primary sources}

The CNN YouTube Debates (2007). http://www.youtube.com/democraticdebate\#qa_ nkavwuWE5eQ. (Accessed: October 29, 2007)

Clinton, Hillary (2007a). I'm In. Posted by hillaryclintondotcom, January 22, 2007. http://www.youtube. com/watch?v=SJuRQZ2ZGTs. (accessed April 19-July 31, 2007).

- (2007b). Let the Conversation Begin 1/22. Posted by hillaryclintondotcom, February 13, 2007. http://www.youtube.com/watch?v $=$ s9g5aBu5ud4. (accessed July 1, 2007).

- (2007c). Let the Conversation Begin 1/23. Posted by hillaryclintondotcom, February 13, 2007. http://www.youtube.com/watch?v=jzxfVPeepGE. (accessed July 1, 2007).

- (2007d). Let the Conversation Begin 1/24. Posted by hillaryclintondotcom, February 13, 2007. http://www.youtube.com/watch?v=Yv1VHd0MZ2Q. (accessed July 1, 2007).

- (2007e). I Need Your Advice. Posted by hillaryclintondotcom, May 16, 2007. http://www. youtube.com/watch?v=3FV7XU-TLMU. (accessed July 10, 2007).

- (2007f.). Pick My Campaign Song: Round 2. Posted by hillaryclintondotcom, May 24, 2007. http://www.youtube.com/watch?v=LClOHUFUC5g. (accessed July 10, 2007; removed by user).

- (12007g). Bill and Hillary Soprano? Posted by PatrickRuffini, June 19, 2007. http://www.youtube. com/watch?v=BfkRjvAYuOc. (accessed July 15, 2007).

Obama, Barack (2007a). My Plans for 2008. Posted by BarackObamadotcom, January 16, 2007. http://www.youtube.com/watch?v $=\mathrm{H} 5 \mathrm{~h} 95 \mathrm{~s} 0 \mathrm{OuEg}$. (accessed April 19-July 31 2007).

- (2007b). Invitation to Dinner with Barack Obama. Posted by BarackObamadot com, June 12, 2007. http://www.youtube.com/watch?v=x-GN7_Zo4mY. (accessed June 14, 2007).

- (2007c). Dinner with Barack Obama. Posted by BarackObamadotcom, July 18, 2007. http://www.youtube.com/watch?v=2P1JR-KBj1c. (accessed July 19, 2007).

\section{Secondary sources}

Associated Press (2006). Google Buys YouTube for $\$ 1.65$ Billion. MSNBC Business News, www.msnbc.msn.com/id/ 15196982. (accessed November 11, 2006).

Androutsopoulos, Jannis (2006). Introduction: Sociolinguistics and computer-mediated communication. Journal of Sociolinguistics 10(4), 419-438.

Arundale, Robert (2006). Face as relational and interactional: A communication framework for research on face, facework, and politeness. Journal of Politeness Research 2(2), 193-217.

Bargiela-Chiappini, Francesca (2003). Face and politeness: New (insights) for old (concepts). Journal of Pragmatics 35(10-11), 1453-1469.

Baym, Nancy (1995). The emergence of community in computer-mediated communication. In Jones, Steven G. (ed.), CyberSociety: Computer-mediated Communication and Community. Thousand Oaks: Sage, 138-163.

Black, Max (1962). Metaphor. In Black, Max (ed.), Models and Metaphors. Ithaca, NY: Cornell University Press, 25-47.

Brown, Penelope and Stephen Levinson. (1987). Politeness: Some Universals in Language Usage. $2^{\text {nd }}$ ed. Cambridge: Cambridge University Press. [1978] 
Bucholtz, Mary and Kira Hall (2005). Identity and interaction: A sociocultural linguistic approach. Discourse Studies 7(4-5), 585-614.

Cruse, Alan (2004 ). Meaning in Language: An Introduction to Semantics and Pragmatics. $2^{\text {nd }}$ ed. Oxford and New York: Oxford University Press.

Du Bois, John W., Susanna Cumming, Stephan Schütze-Coburn, and Danae Padino (eds.) (1992). Discourse Transcription. Santa Barbara Papers in Linguistics (Vol. 4). Santa Barbara: University of California.

Durkheim, Emile (1915). The Elementary Forms of Religious Life. London: G. Allen and Unwin.

Eckert, Penelope (2000). Linguistic Variation as Social Practice. Oxford: Blackwell Publishers Ltd.

Eckert, Penelope and Sally McConnell-Ginet (1992). Think practically and look locally: Language and gender as community-based practice. Annual Review of Anthropology 21, 461-490.

Filliettaz, Laurent (2005). Mediated actions, social practices and contextualization: A case study from service encounters. In Norris, Sigrid and Rodney H. Jones (eds.), Discourse in Action. Introducing Mediated Analysis. London and New York: Routledge, 100-109.

Finnegan, Michael and Matea Gold (2007). Average Citizen is Star of Debate. LA Times Online, July 25, 2007. http://www. latimes.com/news/nationworld/nation/ la-na-debate25jul25,0,3559996.story?coll=la-home-nation. (accessed July 27, 2007).

Forceville, Charles (2006). Non-verbal and multimodal metaphor in a cognitivist framework: Agendas for research. In Kristiansen, Gitte, Michel Achard, René Dirven and Francisco Ruiz de Mendoza Ibáñez (eds.), Cognitive Linguistics: Current Applications and Future Perspectives. Berlin: Mouton de Gruyter, 379-402.

Goffman, Erving (1967). Interaction Ritual: Essays on Face-to-Face Behavior. New York: Pantheon Books.

Hartley, John (1992). Tele-Ology: Studies in Television. London: Routledge.

Holmes, Janet (1995). Women, Men and Politeness. New York: Longman.

Knowles, Murray and Rosamund Moon (2006). Introducing Metaphor. London and New York: Routledge.

Kress, Gunther and Theo van Leeuwen (2006). Reading Images: The Grammar of Visual Design. $2^{\text {nd }}$ ed. London and New York: Routledge. [1996]

Lakoff, George (1987). Women, Fire, and Dangerous Things. What Categories Reveal about the Mind. Chicago: University of Chicago Press.

Lakoff, George and Mark Johnson (2003). Metaphors We Live By. Chicago and London: The University of Chicago Press. [1980]

- (1999). Philosophy in the Flesh. The Embodied Mind and Its Challenge to Western Thought. New York: Basic Books.

Locher, Miriam A. (2004). Power and Politeness in Action: Disagreements in Oral Communication. Berlin: Mouton de Gruyter.

- (2006a). Polite behavior within relational work: The discursive approach to politeness. Multilingua 25(3), 249-267.

- (2006b). Advice Online. Amsterdam and Philadelphia: John Benjamins Publishing Company.

- (2008). Relational work, politeness and identity construction. In Antos, Gerd, Eija Ventola and Tilo Weber (eds.), Handbooks of Applied Linguistics. Volume 2: Interpersonal Communication. Berlin/New York: Mouton de Gruyter, 509-540.

Locher, Miriam A. and Richard Watts (2005). Politeness theory and relational work. Journal of Politeness Research 1(1), 9-33.

- (2008). Relational work and impoliteness: Negotiating norms of linguistic behaviour. In Bousfield, Derek and Miriam A. Locher (eds.), Impoliteness in Language. Studies on its Interplay with Power in Theory and Practice. Berlin: Mouton, 77-99. 
McLuhan, Marshall (1964). Understanding Media: The Extensions of Man. New York: McGraw Hill.

Mendoza-Denton, Norma. (2001). Language and identity. In Chambers, J. K., Peter Trudgill, Natalie Schilling-Estes (eds.), The Handbook of Language Variation and Change. Oxford: Blackwell Publishers Ltd., 475-499.

Messaris, Paul (1994). Visual 'Literacy': Image, Mind, and Reality. Boulder and Oxford: Westview Press.

Meyerhoff, Miriam (2001). Communities of practice. In Chambers, J. K., Peter Trudgill, Natalie Schilling-Estes (eds.), The Handbook of Language Variation and Change. Oxford: Blackwell Publishers Ltd., 526-548.

Min, Seong-Jae (2007). Online vs. face-to-face deliberation: Effects on civic engagement. Journal of Computer-Mediated Communication 12(4). http://jcmc.indiana. edu/vol12/issue4/min.html.

$\mathrm{Ng}$, Sik Hung and James J. Bradac (1993). Power in Language: Verbal Communication and Social Influence. Language and Language Behaviors vol. 3. Newbury Park, CA: Sage Publications, Inc.

Oxford English Dictionary (1989). $2^{\text {nd }}$ ed. Oxford: Oxford University Press [online].

Oxford Collocations Dictionary for Students of English (2002). Oxford: Oxford University Press.

Postman, Neil (2005). Amusing Ourselves to Death: Public Discourse in the Age of Show Business. $2^{\text {nd }}$ ed. New York: Penguin Books. [1985]

Prince, Stephen (2007). Movies and Meaning: An Introduction to Film. 4th ed. New York: Pearson. [1997]

Scollon, Ron (2001). Mediated Discourse: The Nexus of Practice. London: Routledge.

Smith, Hedrick (1988). The Power Game: How Washington Works. New York and Toronto: Ballantine Books.

Tracey, Michael (1995). Non-fiction television. In Smith, Anthony (ed.), Television: An International History. New York: Oxford University Press, 118-147.

Watts, Richard J. (1992). Linguistic politeness and politic verbal behaviour: Reconsidering claims for universality. In Watts, Richard J., Sachiko Ide and Konrad Ehlich (eds.), Politeness in Language: Studies in its History, Theory and Practice. Berlin: Mouton de Gruyter, 43-69.

- (2003). Politeness. Cambridge: Cambridge University Press.

- (2005). Linguistic politeness research. Quo vadis? In Watts, Richard J., Sachiko Ide and Konrad Ehlich (eds.), Politeness in Language: Studies in its History, Theory and Practice, (2nd revised and expanded ed.). Berlin: Mouton, xi-xlvii. [1992] 